\title{
Burocracia e inserção social: um estudo sobre - Ministério da Saúde na gestão do Sistema Único de Saúde (SUS)
}

\section{Bureaucracy and social integration: a study on the Ministry of Health in the management of the National Health System (SUS)}

\author{
Luciana Assis Costa \\ Doutora em Sociologia. Professora adjunta do Departamento de \\ Terapia Ocupacional da Universidade Federal de Minas Gerais. \\ Endereço: Av. Antônio Carlos, 6.627, Campus Pampulha, CEP 31270- \\ 901, Belo Horizonte, MG, Brasil. \\ E-mail: lucianaassis.ufmgळgmail.com

\section{Jorge Alexandre Barbosa Neves} \\ Doutor em Sociologia. Professor associado do Departamento de \\ Sociologia da Universidade Federal de Minas Gerais. \\ Endereço: Av. Antônio Carlos, 6.627, Campus Pampulha, CEP 31270- \\ 901, Belo Horizonte, MG, Brasil. \\ E-mail: jorgeanevesळgmail.com
}

\section{Resumo}

Embora o Sistema Único de Saúde (SUS) seja implementado de forma descentralizada, com forte ênfase municipalista, o papel de formulação e coordenação nacional da política de saúde se mantém sob a responsabilidade do Ministério da Saúde, o que demonstra a importância da esfera federal na condução e indução dessa política.

Este artigo é uma pesquisa qualitativa, na qual as técnicas de coleta de dados foram entrevistas semiestruturadas e análise documental. 0 objetivo foi analisar a estrutura do aparato estatal responsável pela formulação e coordenação da política de saúde brasileira após a década de 1990, a partir da configuração da burocracia do Ministério da Saúde (MS) e as conexões do órgão com as forças societárias do setor. A perspectiva teórica de análise foi o institucionalismo sociológico, apoiado no modelo de autonomia inserida de Peter Evans (1995), somado ao conceito de isomorfismo de DiMaggio \& Powell (1983). Os resultados demonstram que a gestão federal do SUS se encontra distante de um modelo tipo ideal weberiano e os avanços da política de saúde podem, parcialmente, ser explicados pela disseminação de uma forte cultura sanitarista que atuou de forma a compensar a ausência de elementos típicos das burocracias tradicionais na condução da política de saúde.

Palavras-chave: Burocracia; Política de saúde; Institucionalismo sociológico. 


\section{Abstract}

Although the National Health System (SUS) is implemented in a decentralized manner, with strong emphasis on the municipal level, the role of formulating and coordinating national health policy remains the responsibility of the Ministry of Health, which shows the importance of federal level in inducting and conducting that policy.

This study has as its objective the analysis of the state apparatus' structure responsible for the formulation and coordination of healthcare politics after 1990, starting with the configuration of the bureaucracy of the Ministry of Health and its connections with the societal forces involved in this topic. This analysis is supported by the model of "embedded autonomy" theorized by Peter Evans (1995), based in the comparative institutionalist approach, to treat the State not as isolated from the environment, but as sensitive to the surrounding social relations coupled with the concept of isomorphism by Powell and DiMaggio (1983).The study reveals that the federal management of SUS was developed by an extremely vulnerable administrative frame, through analysis of both the recruitment model of the servants of the Ministry of Health headquarters as well as the processes of internal promotion in the sector. Nonetheless, healthcare policy is still recognized nationally, after the consolidation of SUS, as one of the most successful social policies. Advances in health policy can partially be explained by the spread of a strong hygienist culture that led to compensation for the absence of typical elements of traditional bureaucracies in the conduction of health policy.

Keywords: Bureaucracy; Healthcare Policy; Sociological Institutionalism.

\section{Introdução}

O sistema de saúde brasileiro foi constituído a partir de dois aparatos institucionais distintos: a assistência médica individual, de natureza securitária e corporativista, prestada pelo Ministério da Previdência Social e a saúde coletiva, com ênfase na prevenção, que se manteve sob a égide do Ministério da Saúde.

Até final dos anos 1980, a condução da assistência médica brasileira esteve sob a responsabilidade do Ministério de Previdência e Assistência Social e, portanto, apresentava-se fortemente centralizada no âmbito federal, numa relação corporativista com a massa operária e, por sua vez, com forte apelo clientelista com o setor privado de prestação de serviços de saúde. Já a saúde pública, de caráter preventivo e coletivo, manteve-se no âmbito do Ministério da Saúde, criado em 1953, a partir do desmembramento do Ministério da Educação e Saúde. O MS herdou a agenda sanitarista de combate às endemias rurais e epidemias que, até então, estava sob a responsabilidade do Departamento Nacional de Saúde, órgão do Ministério da Educação e Saúde. Da década de 1950 à de 1980, o Ministério da Saúde atuou como gestor das ações de saúde pública, numa concepção universalista, sem que esta fosse uma diretriz priorizada na consolidação do sistema de saúde brasileiro, cunhado pela medicina previdenciária (Machado, 2007).

A partir da abertura democrática, o papel do Estado na condução da política de saúde se altera significativamente, tanto pela forma universal de provisão da assistência à saúde, que substitui o padrão corporativista previdenciário, quanto pela presença de canais de participação que passam a compor a arena decisória da política de saúde. Isso não significa que os padrões clientelistas preeminentes no período ditatorial foram suprimidos da relação entre Estado e sociedade na condução da política de saúde, mas não há como negar que novas relações foram construídas fundamentadas em maior participação social na construção da política de saúde (Nunes, 2010). Após a constituição de 1988, o País passa a contar com um Sistema Único de Saúde (SUS), resultado de um amplo movimento de reforma sanitária, originado em meados dos anos 1970 e que ganha força política e ideológica durante o processo 
de abertura democrática e, especialmente, em meio à crise do sistema de previdência social. Importantes mudanças administrativas também são evidenciadas no aparelho do Estado especialmente quanto ao órgão gestor da política de saúde. A proposta de um sistema integrado de saúde resultou paulatinamente na extinção do Instituto Nacional de Assistência Médica e Previdência Social (INAMPS), órgão gestor da assistência médica previdenciária desde a década de 1970, e na transferência da coordenação do sistema de saúde para o Ministério da Saúde historicamente responsável pela saúde coletiva. Após a atribuição constitucional que oficializa o Ministério da Saúde como órgão gestor do Sistema Único de Saúde, bem como responsável por estabelecer condições para aplicação dos dispositivos contidos na Lei Orgânica de Saúde, as mudanças, tanto das atribuições quanto da adequação da estrutura organizacional para a implementação do novo sistema de saúde, sucedem de forma paulatina.

Tanto a descentralização do sistema quanto a formalização das instâncias colegiadas impactaram diretamente na complexidade do ambiente de condução da política de saúde, e, portanto, na relação entre o Ministério da Saúde e os atores envolvidos no campo da saúde. Aárea da saúde, diferentemente de outras áreas, foi a que mais intensa e precocemente incorporou mecanismos institucionalizados de participação social (Côrtes, 2009). Embora o SUS seja implementado de forma descentralizada, com forte ênfase municipalista, reservando aos mecanismos de participação social um espaço de deliberação e controle das políticas de saúde, desde a década de 1990, o papel de formulação e coordenação nacional da política de saúde se mantém sob a responsabilidade do Ministério da Saúde, que atua como gestor nacional do sistema, o que demonstra a importância da esfera federal na condução e indução dessa política.

A presença cada vez maior do Estado como instituição social, de uma sociedade civil ampliada, e a permanência do aparato burocrático como modelo racional de dominação e condição inevitável para a consolidação do estado democrático, reforçam a importância de recolocar a problemática da burocracia no centro da discussão sobre a relação entre estado e sociedade (Prates, 2004; Evans e col., 1985).

O objetivo deste estudo foi analisar a estrutura do aparato estatal responsável pela formulação e coordenação da política de saúde após a década de 1990, a partir da configuração da burocracia do Ministério da Saúde, órgão que atua como gestor nacional da política de saúde, no que tange aos seus aspectos formais weberianos, padrão de seleção dos servidores públicos e planos de carreira, bem como a relação que este estabelece com a tessitura administrativa envolvida com o setor.

\section{Fundamentação teórica}

O modelo de "autonomia inserida", de Peter Evans, fundamentado na abordagem institucional comparativa, oferece referenciais analíticos para compreender as possíveis formas de a burocracia se modernizar na democracia.

A abordagem institucionalista inverte a imagem neoutilitarista do Estado, ao sustentar o pressuposto de que é a insuficiência da burocracia que prejudica o desenvolvimento e não sua prevalência (Evans, 2004). Evans (2004) discute a necessidade da coexistência entre o grau de insulamento do Estado e imersão da burocracia pública no ambiente externo no qual se encontram as forças societárias, apoiado no pressuposto de que "as decisões dos burocratas sofrem influências de contextos institucionais complexos, com interações historicamente enraizadas e incorporadas em estruturas sociais assimiladas pelos indivíduos que atuam no próprio estado" (Evans, 2004, p. 58).

Nesta linha argumentativa, Evans destaca o desafio contemporâneo imposto ao Estado, e, consequentemente, ao modelo de organização burocrática, no que diz respeito aos novos desenhos institucionais advindos com o processo de democratização que necessitam de uma readaptação do Estado no sentido de construir um modelo de dominação racional-legal que se legitime por meio de um equilíbrio entre insulamento e inserção social. Sobre este ponto, Evans (1995) traz uma importante contribuição ao destacar que a eficiência da burocracia depende, além do grau de burocratização decorrente da seleção meritocrática e dos incentivos da progressão, da relação que se estabelece entre a burocracia com redes externas, que conectam o Estado à sociedade civil por meio de uma "teia administrativa". 
Ou seja, Evans busca compreender a ação do Estado a partir da coexistência entre a condição de autonomia e a inserção social, apoiado nas premissas basilares da burocracia weberiana, de legalidade, impessoalidade, formalidade e universalidade, que coadunam com os princípios fundamentais do Estado de Direito, indispensáveis ao ordenamento democrático da administração pública. Vale esclarecer que a burocracia, definida sob o prisma do Estado moderno, constitui-se o tipo tecnicamente mais puro da dominação racional legal, tendo sua máxima na eficiência do Estado. Neste sentido, a busca da igualdade por meio da aplicação de regras universalistas e impessoais, contrária ao privilégio e ao tratamento discricionário, reforça o argumento de que a burocracia atua inevitavelmente como pré-condição para a consolidação do Estado democrático (Weber, 1999). Tais princípios devem orientar não só a ação dos funcionários quando executam as funções do Estado, mas igualmente a estruturação das carreiras públicas, ou seja, os processos de recrutamento, promoção, avaliação e controle dos atos e omissões dos membros do aparato estatal (Azevedo e Loureiro, 2003).

Todavia, ao trazer à tona a relação entre autonomia do Estado e inserção social Evans (1995) evidencia posições analíticas aparentemente conflitantes. De um lado, o autor defende a posição do insulamento, entendido como certo distanciamento e autonomia do Estado perante os interesses e demandas societárias, como pré-condição necessária ao funcionamento de um Estado racional. Por outro, levanta a discussão sobre como distinguir os benefícios do insulamento dos custos do isolamento e ressalta a necessidade de o Estado conjugar autonomia e inserção na condução das políticas setoriais, considerando que os Estados e estruturas sociais são mutuamente determinantes.

A hipótese de Weber sobre o papel da burocracia ainda é o ponto de partida para a análise da estrutura interna do Estado. Compreender o tipo ideal weberiano permite ainda identificar, numa acepção metodológica, os elementos estruturais formalistas que compõem o Estado moderno, bem como indagar sobre os limites analíticos e empíricos dessa abordagem diante dos desafios colocados ao Estado democrático, advindos especialmente da complexidade do espaço público no qual as políticas são formuladas e implementadas (Weber, 1982, 1985, 1999, 2004).

Evans (2004) parte da observação das estruturas do Estado e as relações entre este e a sociedade e seus impactos em termos de mudanças sociais (Evans, 1995).

\section{Segundo Evans (2004):}

Se por um lado a organização interna dos estados desenvolvimentistas assemelha-se mais à burocracia weberiana, por outro, eles não são isolados da sociedade como define o modelo weberiano. Ao contrário, estão inseridos em um conjunto concreto de alianças sociais que ligam o Estado à sociedade e preveem canais institucionalizados para a negociação contínua de objetivos e planos de ação (p. 38).

O modelo de autonomia inserida analisa a organização burocrática e as bases não burocráticas de solidariedade a partir de duas variáveis analíticas: o grau profissionalização da burocracia, por meio do processo de seleção meritocrático e das formas de promoção interna dos funcionários públicos; e a capacidade de inserção do projeto governamental nas ambições e possibilidades da sociedade (Evans, 1995).

Os elementos de solidariedade não burocráticos são identificados tanto no âmbito interno à burocracia quanto nas relações externas, como reforço da estrutura organizacional formal.

As redes internas de solidariedade geralmente provêm de características comuns da formação dos profissionais que assumem cargos de dirigentes. A formação dos profissionais como elemento de coesão interna à burocracia gera uma coerência e uma identidade corporativa que o mérito por si só não alcança. No entanto, o caráter e as consequências destas redes dependem fundamentalmente do processo de seleção meritocrático. Ou seja, a coerência burocrática interna deve ser vista como uma precondição essencial para a participação efetiva do Estado nas redes externas (Evans, 2004).

A inserção social do Estado é viabilizada empiricamente por uma teia administrativa, que implica em redes externas compostas por conexões concretas que articulam o Estado a grupos sociais particulares com os quais ele compartilha projetos e transformações, além de atuarem como fonte de 
inteligência e consenso no sentido de ampliar a sua competência. Um exemplo destes grupos são as organizações intermediárias (associações), as redes de programas informais e os conselhos deliberativos, sendo esses últimos de natureza híbrida, em que ocorre a maior parte da formação de consenso.

Os vínculos externos permitem que os dirigentes não percam a dimensão do que é efetivamente possível realizar e a habilidade para implementar ações específicas que gerem transformações econômicas ou sociais (Faria, 2006; Evans, 1995). Concomitantemente, a autonomia relativa do Estado o resguarda de interesses imediatos e particularistas que subvertem a sua função pública.

Na mesma linha de raciocínio neoinstitucionalista, que contempla a instituição incluindo não apenas as estruturas organizacionais formais de regras, procedimentos ou normas, mas também, os sistemas de símbolos, esquemas cognitivos e modelos morais que guiam a ação humana e explicam a difusão de práticas (Hall e Taylor, 2003), o conceito de isomorfismo, desenvolvido por DiMaggio e Powell (1983), diz respeito aos mecanismos que emergem do ambiente e produzem padrões comportamentais homogêneos que podem levar à estabilidade e coesão na estrutura burocrática. A definição do conceito de isomorfismo compreende os processos de constrangimentos que forçam a apropriação de uma determinada unidade da população no sentido de aproximar os sets ambientais das demais unidades (DiMaggio e Powell, 1983).

O isomorfismo institucional compreende três mecanismos que agem no sentido de padronizar os comportamentos organizacionais, sendo eles, o mimético, o coercitivo e o normativo. No presente estudo, contudo, destacou-se apenas o último. 0 isomorfismo normativo diz respeito ao processo de mudança decorrente da profissionalização, que resulta da luta dos membros de uma ocupação para definir as condições e métodos de seu trabalho, para controlar a produção dos produtores, e estabelecer uma base cognitiva e legítima para a autonomia das suas ocupações (tarefas/cargos). A homogeneização profissional respalda-se comumente na educação formal ou na legitimidade cognitiva produzida por profissionais/especialistas com formação universitária. Cabe ressaltar o crescimento e elaboração de redes profissionais que inserem nas organizações novos modelos que se difundem rapidamente (DiMaggio e Powell, 1983).

É interessante ressaltar que, de acordo com os autores, burocratização e homogeneização emergem, sobretudo, fora do campo estrutural da organização (DiMaggio e Powell, 1983). Isso significa que, mesmo diante de uma estrutura de Estado aparentemente fragilizada quanto ao seu aparato burocrático, mecanismos advindos do ambiente podem gerar maior capacidade e autonomia do Estado na condução das políticas públicas. Buscando compreender a relação entre Estado e sociedade na política da saúde, o conceito de isomorfismo institucional de DiMaggio e Powell (1983) foi fundamental para identificar os mecanismos que advêm do ambiente externo ao Estado e que podem atuar no sentido de profissionalizar e aumentar a capacidade e autonomia estatal na condução da política de saúde. Esta profissionalização respalda-se comumente na educação formal ou na legitimidade cognitiva produzida por profissionais/ especialistas com formação universitária (DiMaggio e Powell, 1983). Se por um lado, o modelo de Powell e DiMaggio não se vincula diretamente ao modelo de Evans, exceto pela vertente neoinstitucionalista, por outro lado, a concepção de isomorfismo normativo apresentou-se complementar à ideia de autonomia inserida. Tendo em vista que o modelo de Evans não foi completamente corroborado no estudo, dado à evidência de certa eficiência do Estado mediante a escassez de uma estrutura burocrática típica, o conceito de isomorfismo normativo enriqueceu a análise, ao considerar a influência de elementos cognitivos dissipados pela academia e pelo elevado grau de qualificação dos ocupantes de cargos no MS, que parecem reforçar a profissionalização e a capacidade do aparelho de Estado.

Este estudo baseou-se no argumento basilar que a eficiência do Estado está associada à coerência interna da burocracia, somada à conexão com as redes externas, sendo, estas últimas, fonte de inteligência e consenso na condução da política de saúde.

\section{Método}

Trata-se de um estudo qualitativo, de natureza exploratória e indutiva, no qual as técnicas utilizadas 
de coleta de dados primários foram: entrevistas semiestruturadas e a análise documental. Todas as entrevistas foram gravadas e transcritas e, posteriormente, analisadas segundo a técnica de análise de conteúdo.

As entrevistas foram realizadas com onze especialistas da área da saúde, no período de outubro de 2010 a abril de 2011, sendo que um dos critérios de seleção dos entrevistados foi a experiência direta na condução da política de saúde no âmbito federal da década de 1990 em diante. Dentro desse grupo, encontram-se aqueles com vínculos diretos com o Ministério da Saúde, consultores externos, representantes do Conselho Nacional de Secretarias Municipais de Saúde (CONASEMS) e do Conselho Nacional de Secretários Estaduais (CONASS), os quais tiveram uma atuação efetiva na Comissão Intergestores Tripartite (CIT), bem como representante do Conselho Nacional de Saúde (CNS) e das organizações acadêmicas Associação Brasileira de Saúde Coletiva (ABRASCO) e o Centro Brasileiro de Estudos de Saúde (CEBES).

Em relação aos cargos ocupados pelos entrevistados, selecionaram-se aqueles que representavam tanto a burocracia do MS quanto os órgãos que compõem a teia administrativa do setor. Assim têm-se: secretário de assistência à saúde; consultores do Ministério da Saúde; servidores de carreira com cargos de coordenação geral de Inovação Gerencial e Coordenação de Gestão de Recursos Humanos; Coordenação da Secretaria Técnica da CIT; Presidência do CNS; secretário executivo do CONASEMS; Presidência do CONASS; vice-presidência da ABRASCO.

Tendo em vista as limitações desse tipo de estratégia metodológica, outras fontes primárias foram utilizadas com destaque para a análise documental (leis federais, normas e portarias ministeriais selecionadas, documentos oficiais do Ministério da Saúde). Ademais, foram fundamentais o acesso a informações de bancos de dados oficiais, tais como o Boletim Estatístico de Pessoal, elaborado pelo Ministério de Planejamento, bem como a um grande número de trabalhos de outros autores sobre áreas e temas específicos da política nacional.

Também foi levantado o perfil profissional de dezoito dirigentes que ocuparam as secretarias de assistência à saúde e a executiva, em onze gestões ministeriais distintas, utilizando a análise curricular disponível em ambiente virtual.

O estudo teve como epicentro a abordagem neoinstitucionalista sociológica sob a ótica de Peter Evans e Powell \& DiMaggio, que permitiu analisar a ação do Estado numa perspectiva que transcende, tanto a linha do individualismo metodológico, quanto dos modelos estruturalistas.

\section{Resultado e discussão}

Para apresentação e análise dos resultados, dividiu-se a seção em três tópicos. Um primeiro busca identificar a composição dos cargos administrativos do MS, ressaltando a sede do ministério, lócus de formulação e coordenação da política. No segundo, levantou-se o perfil dos dirigentes que ocuparam as secretarias executiva e de assistência à saúde do ministério, destacando a formação profissional e experiência no setor, e por fim, apresentou-se a teia administrativa da saúde, com destaque para as relações entre a burocracia e as forças societárias envolvidas com a política pública.

\section{Morfologia do Ministério da Saúde: composição dos cargos administrativos}

Em relação aos aspectos formais da burocracia, tais como o padrão de recrutamento dos servidores do MS, bem como as carreiras do setor, os dados empíricos demonstram que o SUS foi implantado por um Estado que se encontra distante de uma burocracia típico-ideal.

Após 24 anos sem a realização de concursos públicos para o MS, não é difícil compreender o fato de que, até 2005, apenas um terço do quadro administrativo da sede do Ministério era composto por servidores de carreira. A maioria dos funcionários era vinculada por meio de contratos temporários ou terceirizados. O quadro administrativo do MS no período de 1990 a 2005 é alterado basicamente por três fatores: desativação ou incorporação no âmbito do Ministério, de órgãos que compunham o antigo sistema de saúde, vinculados à previdência social; contratos temporários e, finalmente, o crescente número de servidores que atingem tempo de aposentadoria. Todavia, a grande transformação do quadro administrativo do MS ocorreu em 1993, com 
a extinção do INAMPS e o deslocamento de mais de 100 mil funcionários da antiga estrutura para o MS.

No período de 2005 a 2010, os concursos públicos foram retomados, após mais de duas décadas, devido à forte pressão do Ministério Público do Trabalho, decorrente das irregularidades de mão de obra praticada no âmbito da administração pública federal direta.

No período de 2005 a 2011, verifica-se um aumento de $13 \%$ no total de servidores do MS, de 160.459 para 181.573. Esse aumento é expressivo no quantitativo de servidores dos hospitais próprios do MS, que elevou de 7.093 para 17.845 (Brasil, 2010).

Em relação aos servidores inativos, nesse período houve um aumento de 3.515 e, em 2011, o quantitativo de inativos no MS representava $59,23 \%$ do total dos servidores lotados no Ministério. No que se refere aos servidores ativos, entre 2005 e 2011, houve um aumento de $21 \%$, o que representou um acréscimo de 15.819 servidores ativos vinculados ao Ministério (Brasil, 2010).

Em 2011, do total de 72.237 servidores ativos, 26.721 dividiam-se entre a sede do MS, os núcleos estaduais e os hospitais próprios, e a grande maioria, que correspondia a 46.318 eram cedidos ao SUS e aos hospitais universitários, sendo estes em menor número. Contudo, do total de 72.257 servidores ativos, aproximadamente 10 mil já se encontram em abono de permanência, ou seja, com tempo hábil para aposentadoria (Brasil, 2010).

Em 2005, conforme dados disponibilizados pelo MS, havia 9.762 lotados nesse setor governamental com vínculos de terceirizados, contratos temporários da União e consultores contratados por organismos internacionais, sendo que, pelo menos, a metade (5.096) se encontrava nos hospitais e em institutos próprios do MS.

Em relação à sede do Ministério da Saúde, tal como indicado na tabela abaixo, até o ano de 2005, atuavam 3.616 servidores, sendo que, desse total, apenas $31 \%$ era composto por servidores concursados. Por outro lado, $69 \%$ encontravam-se em situação de contratos terceirizados ou consultorias vinculadas a organismos internacionais e uma pequena parte vinculada ao Contrato Temporário da União (CTU).

\section{Tabela I - Total de força de trabalho lotada na sede do Ministério da Saúde por situação de vínculo no período 2005/2011}

\begin{tabular}{|c|c|c|c|c|c|c|}
\hline Situação de vínculo na sede do MS & \multicolumn{2}{|c|}{2005} & \multicolumn{2}{|c|}{2009} & \multicolumn{2}{|c|}{2011} \\
\hline Servidores efetivos & 1.138 & $31 \%$ & 1.198 & $33 \%$ & 1.823 & $57 \%$ \\
\hline Terceirizados Lotados no MS & 1.189 & $33 \%$ & 1.247 & $35 \%$ & Sem informação & Sem informação \\
\hline Consultores Lotados no MS & 1.043 & $29 \%$ & 912 & $25 \%$ & 1.030 & $32 \%$ \\
\hline CTU - Contrato Temporário da União & 246 & $7 \%$ & 238 & $7 \%$ & 328 & $11 \%$ \\
\hline Total Servidores & 3.616 & $100 \%$ & 3.595 & $100 \%$ & - & - \\
\hline
\end{tabular}

Fonte: Elaboração própria a partir de dados cedidos pela secretaria executiva do MS.

A mudança no quadro administrativo da sede do Ministério da Saúde torna-se mais visível no período de 2009 a janeiro de 2011, quando verifica-se um aumento de 625 servidores efetivos, sendo que esse grupo passou a representar mais de $50 \%$ do quadro de funcionários da sede do MS. Em decorrência do aumento de servidores de carreira, foi substituída pelo menos a metade do número de terceirizados existentes em 2009.

Os demais vínculos de consultores e Contrato Temporário da União se mantiveram, sendo que o
CTU aumentou $37 \%$, de 238 para 328 e ao número de consultores foram somados mais 100 profissionais.

Em 2011, no total de 3.181 servidores da sede do Ministério da Saúde, 1.030, ainda eram preenchidos por consultores.

Os servidores efetivos lotados na sede do MS ocupam basicamente dois tipos de carreiras, o Plano de Classificação de Cargos (PCC) e a carreira de Seguridade Social e Trabalho, ambas caracterizadas pela falta de incentivos profissionais adequados (Abrúcio, 2007). A gestão central do Ministério não 
dispõe de uma referência moderna de carreira, que valorize de forma efetiva seus recursos humanos e seja um esteio na continuidade de suas políticas e ações. Contudo, essa é a situação que prevalece em grande parte da administração federal.

Este quadro demonstra como o sistema único de saúde foi formulado e coordenado por meio de uma estrutura burocrática frágil, na qual a seleção por concurso, condição sine qua non de uma burocracia meritocrática, não constituiu forma hegemônica de composição do quadro administrativo da saúde até 2009. Embora esse cenário não seja particular da saúde, o montante de funcionários contratados é bastante significativo no setor, tendo em vista que o setor constitui o segundo em quantitativo de cargos, depois da educação. No entanto, esse panorama provoca uma indagação a respeito de como foi possível coordenar a transição e a consolidação do Sistema Único de Saúde, sustentada num modelo burocrático extremamente instável no âmbito do Ministério da Saúde.

\section{O Perfil dos dirigentes das secretarias executivas e de assistência à saúde do MS}

Tendo em vista o fato de que na saúde as carreiras não influenciam a nomeação dos cargos comissionados do alto escalão, foi de extrema relevância identificar quem foram os profissionais que ocuparam os cargos de direção do MS, em relação à formação e experiência profissional anterior à ocupação do posto, e quais os critérios de nomeação para estes cargos. Para tanto, foram selecionados 18 cargos de natureza técnico-política, de nível Direção e Assessoramento Superior (DAS) 6 que ocuparam as secretarias de maior poder político no Ministério, tais como a secretaria executiva e a secretaria de assistência à saúde, durante quatro gestões ministeriais distintas.

Em primeiro lugar, a homogeneidade na formação dos secretários. Dos 18 analisados, 15 são médicos, 1 bioquímico, 1 economista e 1 administradora de empresas. A grande maioria dos secretários é formada por homens, apenas duas mulheres ocuparam tais postos. Também se destaca o alto nível de escolaridade dos ocupantes das secretarias do Ministério da Saúde, dos 18 secretários, 2 são especialistas, 3 mestres, 10 possuem o título de doutor, sendo que 9 fizeram doutorado na área da saúde coletiva e se intitulam sanitaristas. Dos 3 secretários que não possuem pós-graduação, 2 são médicos e 1 bioquímico. A qualificação dos profissionais que atuaram nas secretarias do MS de alguma forma demonstra que estes cargos embora sejam de indicação política, foram preenchidos por profissionais altamente capacitados tecnicamente, e, ainda, grande parte com uma formação sanitarista em núcleos acadêmicos de excelência na área, UNICAMP, UERJ, ENSP/FIOCRUZ e USP.

Outro ponto diz respeito à experiência dos dirigentes na gestão do SUS. A maioria dos secretários do MS já atuou como gestor municipal e ou estadual de saúde, e alguns já haviam presidido os conselhos de secretários municipais e estaduais ou atuaram como professores titulares de universidades federais. Ainda em relação à origem dos ocupantes de cargos de secretário no Ministério da Saúde, um aspecto particular à política de saúde diz respeito a uma notável sobreposição entre aqueles que se encarregam de formular e os que se dedicam a implementar, gerir e até mesmo avaliar as mudanças políticas propostas no âmbito do SUS. Constata-se um número significativo de executivos, assessores técnicos do MS, assim como assessores do CONASS, CONASEMS e do CNS, que já ocuparam cargos de secretários ou subsecretários de saúde em Estados e municípios. Ainda se verifica que vários atores responsáveis pela formulação e implementação de políticas de saúde trabalharam em centros de pesquisa. Além da circulação dos profissionais entre as várias funções nos aparelhos de Estado, ocorre na área da saúde um outro tipo de movimento muito peculiar: há numerosos casos de técnicos que migram entre municípios, até de diferentes Estados, desempenhando a função de secretários municipais de saúde. Vários deles se encontram na terceira experiência de gestão ${ }^{1}$.

Quanto aos critérios de nomeação dos cargos de secretários, primeiramente vale destacar que

\footnotetext{
1 MENICUCCI, T. M. et al. A reforma do sistema de saúde no Brasil: descentralização como diretriz e igualdade como princípio, 1999. Relatório de pesquisa.
} 
na saúde a carreira não constitui uma condição de acesso aos cargos de DAS 6. Isto significa que praticamente todos os cargos possuem forte peso político, por serem indicados por critério de confiança, e, portanto, assumidos por profissionais sem vínculo com o Estado. Apenas um destes foi ocupado por servidor de carreira. No entanto, de acordo com as entrevistas, a indicação dos cargos de secretários do Ministério da Saúde não estava vinculada ao critério partidário, mas sim técnico e de certa forma, ideológico, especialmente nos primeiros anos da consolidação do SUS. O relato do representante do Núcleo de Educação em Saúde Coletiva (NESCON) reforça este argumento:

Não era um critério partidário é curioso, não era definitivamente [...] Então politicamente eram pessoas engajadas muito mais num movimento sanitário, não o original o primeiro movimento sanitário, mas seguramente um na gestão municipal, outro na carreira universitária, outro na gestão hospitalar [...]

Nesta mesma direção, o ex-secretário da Secretaria de Atenção à Saúde (SAS) afirma que existem pessoas extremamente comprometidas com o sistema que permanecem ainda hoje no MS. Este perfil foi de alguma forma alterado em pelo menos dois momentos: o primeiro na gestão do FHC, quando por uma única vez, a secretaria executiva foi ocupada por um economista e não um profissional médico ou da área da saúde. Neste momento verifica-se uma estreita relação entre a secretaria executiva do MS e a área econômica do governo, demonstrando em parte, que a ocupação dos cargos da área da saúde não se concentrava mais apenas na comunidade profissional de sanitarista, que apesar das divergências internas, convergia na defesa intransigente da ampliação de recursos para o setor ${ }^{2}$. E um segundo momento, na gestão do governo Lula, na qual o critério partidário teve uma relevância maior na composição das secretarias do ministério, gerando uma fragmentação interna do Ministério da Saúde. Os relatos ilustram a "partidarização" e certo loteamento na composição dos cargos do MS:

No governo Lula meio que se inaugurou outro pata- mar. As pessoas vieram principalmente para esses cargos com uma vinculação partidária definida, não só de partido como de subgrupo partidário. Porque houve, eu diria, uma politização não necessariamente no bom sentido da palavra da saúde que no governo Serra, no governo Fernando Henrique isto era menos forte (ex-secretário municipal; professor titular da UNB; ex-consultor do Ministério da Saúde).

Nos últimos dois governos do presidente Lula houve um loteamento partidário do ministério, certa partidarização das áreas do ministério. Então éassim, tem as secretarias do PT e as que são do PMDB. $O$ que tem complicado muito certa unidade, embora o conflito entre as áreas sempre tenha havido, cada secretaria do ministério intercepta uma série de redes de assuntos ou de comunidades de políticos que buscam interferir nas políticas desta área de forma mais ou menos interessada, é lobista mesmo em alguns casos. (Representante do NESCON)

Os relatos também nomeiam a natureza intermitente da burocracia do MS e ainda confirmam o que já fora destacado anteriormente, sobre a experiência dos seus dirigentes em outros cargos executivos, tais como gestores municipais ou estaduais, ou vinculados à academia. As experiências de gestão trazidas pelos dirigentes foram avaliadas positivamente como geradoras de inovação e mudanças que se refletiram na condução da política de saúde no âmbito do Ministério.

o Ministério da Saúde foi ocupado por um tipo de funcionário que não era de carreira. Eu chamo de burocracia adventícia [...] Então que funcionário é esse? Por um lado, geralmente ex-gestores ou gente ligada à academia que veio trazida pelo dirigente do momento. Eu próprio estive presente na época da reformulação da norma 93, na 96 eu não estava no ministério mas como uma pessoa fora da carreira. Eu era um ex-gestor público, fui secretario municipal de saúde e vim trabalhar no ministério em Brasília e participei da elaboração da Norma Operacional Básica(NOB). Então eu acho que isso talvez diferencie [...] Ela traz realmente

2 MENICUCCI, T. M. et al. A reforma do sistema de saúde no Brasil: descentralização como diretriz e igualdade como princípio, 1999. Relatório de pesquisa. 
um arejamento de quem estava na gestão, quem estava dirigindo o secretário municipal de saúde, o secretário estadual de saúde [...] (ex-secretário municipal; professor titular da UNB; ex-consultor do Ministério da Saúde).

[...] E se não tivesse essa confusão que é o Brasil e essa quantidade de cargos de confiança, isso possibilitou a mudança senão essa turma estaria mandando até hoje. Eu acho que você ter uma burocracia estável é um fator importante até para a democracia para ter estabilidade das políticas $e$ etc., mas também pode ser uma faca de dois gumes. Você pode perpetuar uma estrutura extremamente conservadora. Por exemplo, a educação não teve uma reforma com os mesmos contornos que teve a saúde (Representante do NESCON).

Assim, a mobilidade dos dirigentes que assumem as secretarias do MS, em esferas de formulação, implementação e controle do sistema de saúde não deixa de constituir um mecanismo de articulação entre o ambiente interno do ministério e os interesses subnacionais e societários do setor. Além de favorecer a construção de uma cultura profissional que perpassa as diferentes esferas de atuação do governo e que, portanto, constitui um elemento organizacional gerador de estabilidade institucional na política de saúde. De acordo com Paim (2007), é difícil discriminar o movimento social de saúde, do movimento dos profissionais e dos gestores, pelo fato de estarem de alguma forma, sempre muito imbricados.

\section{A teia administrativa da saúde}

A delimitação dos órgãos que integram a teia administrativa da saúde foi baseada tanto pela relevância destas organizações no processo de reorientação do sistema de saúde, quanto pela formalidade que eles obtiveram após a constituição do SUS. Instituída a saúde como direito e dever do Estado na constituição de 1988, a Lei Orgânica da Saúde - LOS (Leis 8.080/9o e 8.142/9o) regulamenta o sistema de saúde por meio de diretrizes basilares de implementação da política, tais como a descentralização político-administrativa, com ênfase na municipalização da assistência, bem como a participação de instâncias colegiadas na condução do SUS. Amplia-se a teia administrativa da saúde, termo cunhado por Evans (1995), ao referir-se às redes externas que conectam o Estado por meio da sua burocracia à sociedade civil.

Nota-se que a teia administrativa da saúde é composta basicamente por órgãos vinculados diretamente ao poder executivo e a órgãos representantes da academia.

No âmbito federal, tem-se o CNS, como instância máxima decisória das políticas de saúde juntamente com as conferências, bem como o CONASS e CONASEMS, colegiados de representação dos secretários municipais e estaduais que compõem a CIT, fórum de caráter administrativo que atua como espaço de pactuação e negociação entre as unidades subnacionais e o MS. E como organizações intermediárias estão o CEBES e a ABRASCO, entidades integrantes do movimento sanitário, representantes da academia na formação de um coletivo crítico sobre o sistema de saúde.

No que se refere à qualidade da relação entre a burocracia do MS e os canais de participação, sejam os vinculados à sociedade civil, tais como o Conselho Nacional de Saúde, as Conferências e as associações acadêmicas, bem como os internos a burocracia estatal, tais como a Comissão Intergestores Tripartite, o CONASS, o CONASEMS, as entrevistas revelam que embora esses espaços de articulação estejam oficialmente integrados ao desenho estatal, uma atuação mais efetiva destes órgãos ainda depende definitivamente de laços personalísticos com dirigentes que assumem o MS.

Embora o Conselho Nacional de Saúde seja oficialmente reconhecido como a instância máxima decisória da política de saúde, o estudo demonstra a falta de legitimidade e institucionalidade do órgão diante dos processos decisórios da saúde, especialmente devido aos problemas de sub-representatividade do Conselho, do aparelhamento dos interesses corporativistas somados à falta de engajamento dos dirigentes do MS com esta instância decisória (Silva e col., 2009).

A falta de uma articulação mais sinérgica entre o Conselho Nacional de Saúde e o Ministério indica que a burocracia da saúde relaciona-se de forma débil com um importante mecanismo de inserção social, o que, sem dúvida, compromete a eficiência do Estado para conduzir a política do setor. No 
entanto, mecanismos administrativos internos à burocracia, tal como as comissões intergestores, parecem, no caso da saúde, reduzir o impacto da fragilidade dos Conselhos, ao atuarem como fator de inserção social da burocracia do MS no âmbito das unidades subnacionais.

A Comissão Intergestores Tripartite (CIT), órgão de pactuação entre o MS e gestores municipais e estaduais, desde 1993, participa diretamente não apenas das decisões operacionais do Sistema Único de Saúde, mas também do processo de formulação da política. Tanto as entrevistas quanto a literatura (Gerschman e Santos, 2006; Levcovitz e col., 2001; Menicucci, 2007; Côrtes, 2009) salientam que as comissões intergestores passaram a ser as principais arenas institucionais de tomada de decisão sobre a política de saúde no País. Isto significa que essas comissões reduziram de alguma forma o espaço de atuação dos Conselhos. A CIT e a Comissão Intergestores Bipartite (CIB) estão integradas pela tecnoburocracia de primeiro escalão, o que lhes permite cumprir papel arbitral crucial nas complicadas negociações relativas à descentralização política, administrativa e financeira envolvidas no SUS. Entretanto, à medida que assumem maior número de decisões, é inevitável o surgimento de conflitos de competência com os Conselhos de Saúde, produzindo as típicas tensões entre política e burocracia na democracia (Labra, 1988).

A representante da CIT ilustra, na sua fala, a inexistência de uma relação orgânica e sinérgica entre o CNS e a CIT:

[...] existem assuntos da tripartite que passam ao largo do CNS e que deveriam ser aprovados pelo órgão colegiado. O mais grave é que as pautas dos dois fóruns são distintas, deveria ter uma sintonia, mas não tem nenhuma proximidade.

A partir da segunda metade da década de 1990, praticamente todas as questões que dizem respeito ao financiamento, à descentralização da estrutura de gestão do SUS e à operacionalização do sistema passaram a ser discutidas nessas instâncias (Levicovtiz e col. 2001).

No âmbito da tripartite, verifica-se maior simetria de informações entre os integrantes, dada a estrutura organizacional dos Conselhos de Gestores e do próprio MS, que dispõe de equipes altamente capacitadas para conduzir as discussões no âmbito deste fórum.

No entanto, a atuação do CONASS e do CONASEMS varia de acordo com cada gestão do MS. Embora se verifique maior equilíbrio de forças no âmbito da tripartite, características particulares dos gestores impactam na dinâmica da CIT. De uma maneira geral, o Ministério dispõe de forte poder indutor das decisões políticas da saúde, especialmente pelo fato de ser o órgão que concentra o financiamento do sistema.

Conforme relato do representante do CONASS, a relação entre o MS e os conselhos gestores ainda não está totalmente consolidada, porque no fundo há um desejo do MS em fazer a dominação dos entes federados. Mas hoje se tem uma relação orgânica, institucional e bastante madura.

Ainda no sentido de qualificar a relação entre o MS e os conselhos gestores, segundo representante da CIT:

O Ministério sempre exerce o papel de condução dos trabalhos da comissão, mas isto não significa necessariamente um maior poder decisório do Ministério sobre os demais representantes [...] as decisões com CONASS e CONASEMS é uma possibilidade de construção de negociação. Se o Ministério não apresenta um argumento forte para defesa da sua proposta, a discussão não tem acordo. O Ministério pode até publicar uma política ou processo à parte das decisões tripartite. $\varepsilon$ isto acontece muito. Inclusive, decisões que impactam na organização do sistema, nos Estados e nos municípios e que não tiveram a discussão no âmbito da tripartite.

O representante do CONASS destaca a importância da composição dos dirigentes do MS na condução, pactuada ou não com os conselhos gestores, das decisões internas do setor:

A composição do Ministério da Saúde é determinante para a relação entre o Ministério e os Conselhos Gestores de Secretários. Dependendo da condução que der o Ministro da Saúde, você tem uma relação de conjunto que pode ser negociada na CIT. Mas, por outro lado, se a equipe for fragmentada, a atuação dos conselhos de gestores se dirige por pactuações individualizadas dentro de cada um dos seus interesses.

Ainda segundo relato da representante da CIT: 
Tem períodos interessantes em que se discute o rumo que se pretende para o sistema, da necessidade de mudanças de questões estruturantes como financiamento, trabalhar a política de forma mais integrada. Na primeira gestão do governo Lula, espaço da CIT era mais democrático, de construção coletiva, mais político, discutia-se questões que impactavam na organização do sistema. Nos últimos três anos de governo, o espaço tornou-se muito burocrático, trabalhou minutas de portarias, de políticas fragmentadas, ao contrário de um espaço para discutir temas estruturantes do sistema. Depende da característica dos gestores ou dirigentes, a dinâmica da CIT também é alterada.

A constituição de uma instância de pactuação no âmbito do executivo nacional representa um mecanismo extremamente importante no fortalecimento da burocracia federal da saúde, primeiro por compartilhar as decisões do Ministério com gestores que contam com uma equipe técnica e de consultores altamente qualificada, e que trazem uma vivência das suas experiências locais, e ao mesmo tempo, garante a inserção social do Ministério no âmbito das unidades federadas. A CIT auxilia tanto na normatização quanto na profissionalização nos Estados e municipios para a gestão do Sistema Único de Saúde.

No que tange às associações acadêmicas, CEBES e ABRASCO, estas atuam de forma similar à ideia de isomorfismo normativo, ao construir uma base cognitiva e legítima em relação ao modelo de saúde pública, no sentido de tornar mais similar os comportamentos e atitudes dos profissionais na condução da política de saúde.

A relação do CEBES com o Ministério da Saúde foi descrita como uma parceria marcada por um posicionamento independente da entidade nas suas análises e críticas à política de saúde, já que não apresenta um vínculo formal com o órgão, mas ao mesmo tempo pautadas nos temas que surgem no âmbito do ministério (Representante do CEBES).

Desde a década de 1970, o CEBES atua como um importante centro de formação política dos gestores da saúde e defensor dos princípios basilares do SUS:

Muitos integrantes do CEBES ocuparam cargos importantes no Ministério da Saúde e em secretarias estaduais e municipais. Embora o CEBES seja uma entidade vinculada à academia, ela se pauta mais pela política e menos pela pesquisa científica. A tônica do CEBES sempre foi voltada para a instituição política de saúde. Portanto, é um organismo importante na formação de líderes políticos na área da saúde, que atingem postos de comando no âmbito nacional e outras áreas estaduais e municipais. É uma escola importante e diversos dos seus dirigentes são aproveitados no sistema de saúde (Representante do CEBES).

Representante da CIT ressalta o papel desempenhado pelo CEBES junto à política de saúde e destaca que:

Além de estar presente nas conferências, nos períodos de transição do Ministério, a academia discute com os candidatos inclusive os presidenciáveis. No dia a dia, há uma interface do MS com a academia no desenvolvimento de estudos e pesquisas que são apropriadas no sistema. Hoje, além de pesquisas epidemiológicas, há estudos sobre planejamento e gestão, organização dos serviços. Geralmente, a academia defende a concepção do Estado como provedor do direito à saúde. A academia e os secretários prezam pela ocupação de técnicos que são defensores do sistema no âmbito dos dirigentes.

Todavia, o representante do CEBES chama atenção para o fato de que a composição dos dirigentes e atitudes pessoais delineiam a relação entre o CEBES e o Ministério da Saúde.

Quando o ministro Temporão assumiu o Ministério, por ele já ter sido integrante do CEBES, ficamos na expectativa de haver uma aproximação maior entre a entidade e o órgão, um trânsito mais fácil, inclusive na montagem do seu gabinete, algo que não aconteceu naquela gestão. Por outro lado, o ministro Alexandre Padilha já aponta uma relação diferente, o CEBES tal como outras entidades, foi convidado a fazer uma crítica mais próxima e aberta ao ministério.

A cultura sanitarista disseminada tanto pela academia quanto pela presença de profissionais com formação em saúde pública e saúde coletiva que ocupam as secretarias do MS é um fator extremamente relevante para a condução da política de saúde, visto que mesmo diante da constatação de um enfraquecimento do movimento sanitário após a constituição do SUS, acadêmicos e gestores sim- 
patizantes do movimento, não deixaram de marcar presença nos espaços institucionalizados de gestão da política de saúde, atuando como mecanismo de coesão e profissionalismo no interior do Estado.

Se por um lado, a premissa de Evans sobre a coerência burocrática interna como pré-condição para a participação efetiva do Estado nas redes externas não tenha sido totalmente corroborada no estudo, dada ausência de uma burocracia típico-ideal no âmbito do MS, por outro lado, o conceito de isomorfismo normativo trouxe uma perspectiva complementar de análise, ao demonstrar que a presença de um elevado grau de qualificação da tecnocracia da saúde tende a aumentar a racionalidade e autonomia do Estado, mesmo diante da falta de elementos típicos burocráticos.

\section{Considerações finais}

Conforme demonstram os dados empíricos, a gestão federal do SUS foi desenvolvida por um quadro administrativo extremamente vulnerável, quando analisado o padrão de recrutamento dos servidores da sede do MS, bem como os processos de promoção interna do setor.

Os achados empíricos explicam parcialmente os avanços da política de saúde, não obstante, a presença de um aparato estatal caracterizado por seu baixo grau de coesão e de meritocracia no âmbito do MS.

As principais contribuições desta pesquisa foram demonstrar, primeiramente, que uma forte cultura profissional advinda de um elevado grau de qualificação de técnicos e gestores pode compensar a ausência de elementos típicos das burocracias tradicionais. 0 nível de qualificação profissional da tecnocracia sanitarista é extremamente alto (conta, de modo geral, com formação pós-graduada nas principais escolas de saúde pública do País), o que só reforça o peso da cultura profissional e do conhecimento produzido na academia, bem como do posicionamento dos acadêmicos com relação às políticas do setor, reforçando, assim, o mecanismo de isomorfismo profissional.

Portanto, pode-se identificar que, na ausência de uma burocracia típico-ideal - pois está ausente o elemento da relativa estabilidade nas carreiras - mecanismos isomórficos, em particular o norma- tivo, desempenham um importante papel no campo organizacional da saúde, no Brasil.

Segundo, ilustrar a aplicabilidade do modelo proposto por Peter Evans associado ao conceito de isomorfismo normativo de Powell e DiMaggio, para o entendimento das políticas de saúde no Brasil. Sobre este arcabouço teórico, vale destacar que o estudo traz uma leitura original sobre a relevância de mecanismos que emergem fora do Estado, que atuam na profissionalização da administração pública, aumentando a capacidade e autonomia estatal na condução de uma política social. Finalmente, deve-se ressaltar que não se espera aqui esgotar o modelo teórico aplicado a todas as variáveis e mecanismos explicativos do fenômeno empírico analisado.

A partir dos resultados encontrados na presente pesquisa, propõe-se, portanto, a hipótese de que, na ausência de uma burocracia ideal-típica, o papel que esta desempenharia na formulação e condução das políticas públicas (no modelo proposto por Evans, 1995) pode ser ocupado por uma tecnocracia altamente profissionalizada, mesmo que lhe faltem elementos básicos das burocracias tradicionais, em particular a estabilidade. Em outras palavras, propõe-se a hipótese de que a autonomia relativa que, segundo Evans (1995), seria um dos elementos indispensáveis ao sucesso de uma política pública - não necessariamente necessita da presença de uma burocracia tradicional para se fazer presente. O papel de controle social que advém da autonomia burocrática poderia, assim, ser compensado pelo isomorfismo normativo resultante de uma forte cultura profissional.

Finalmente, parece correto, também, afirmar que os mecanismos de participação social da saúde ficaram fundamentalmente determinados pelo desenho institucional do aparato estatal. Isto significa que a participação social atua praticamente como uma extensão da burocracia federal, ou seja, a teia administrativa da saúde encontra-se imbricada de alguma forma em mecanismos de pactuação internos ao MS, tal como a CIT ou, de uma maneira menos consolidada, os órgãos híbridos de participação como o CNS. Esse tipo de relação entre o Estado e a sociedade civil representaria o segundo elemento fundamental para eficiência do Estado, proposto por Evans (1995), qual seja, a “inserção social”. 


\section{Referências}

ABRÚCIO, F. L. Trajetória recente da gestão pública brasileira: um balanço crítico e a renovação da agenda de reformas. Revista de Administração Pública, Rio de Janeiro, v. 41, p. 6786, 2007. Número especial.

AZEVEDO, C. B.; LOUREIRO, M. R. Carreiras públicas em uma ordem democrática: entre os modelos gerencial e burocrático. Revista do Serviço Público, Brasília, DF, v. 54, n. 1, p. 45-6o, 2003.

BRASIL. Ministério do Planejamento, Orçamento e Gestão. Boletim Estatístico de Pessoal.n. 176. Brasília, DF, dez. 2010. Disponível em: <http://www.planejamento.gov.br/secretarias/ upload/Arquivos/servidor/publicacoes/boletim estatistico_pessoal/2010/Bol176_Dez2010.pdf >. Acesso em: 10 jan. 2011.

CÔRTES, S. V. et al. Conselho Nacional de Saúde: histórico, papel institucional e atores estatais e societais. In: (Org.). Participação e saúde no Brasil. Rio de Janeiro: Fiocruz, 2009. p. 41-72.

DiMAGGIO, P. J.; POWELL, W. W. The iron cage revisited: institutional isomorphism and collective rationality in organizational fields. American Sociological Review, Nashville, v. 48, n. 2, p. 147-16o, 1983 .

EVANS, P.; RUESCHEMEYER, D.; SKOCPOL, T. Bringing the state back in. Cambridge: Cambridge University,1985.

EVANS, P. Embedded autonomy: states and industrial transformation. Princeton: Princeton University, 1995.

EVANS, P. Autonomia e parceria: estados e transformação industrial. Rio de Janeiro: UFRJ, 2004 .

FARIA, C. F. Fóruns participativos, controle democrático e a qualidade da democracia no Rio Grande do Sul: a experiência do governo Olívio Dutra (1999 - 2002). Revista Opinião Pública, Campinas, v. 12, n. 2, p. 378-406, 2006.
GERSCHMAN, S.; SANTOS, B. M. A. O sistema único de saúde como desdobramento das políticas de saúde do século XX. Revista Brasileira de Ciências Sociais, São Paulo, v. 21, n. 61, p. 177-227, 2006.

HALL, P.; TAYLOR, R. As três versões do neoinstitucionalismo. Lua Nova, São Paulo, n. 58, p.193-223, out. 2003.

LABRA, E. L. Proposições para o estudo da relação entre política, burocracia e administração no setor saúde brasileiro. Cadernos de Saúde Pública, Rio de Janeiro, v. 4, n. 1, p. 33-48, 1988.

LEVCOVTIZ, E.; LIMA, L. D.; MACHADO, C. V. Política de saúde nos anos 9o: relações intergovernamentais e o papel das normas operacionais básicas. Ciência \& Saúde Coletiva, Rio de Janeiro, v. 2, n. 6, p. 269-291, 2001.

MACHADO, C. V. Direito universal, política nacional: o papel do Ministério da Saúde na política de saúde brasileira de 1990 a 2002. Rio de Janeiro: Museu da República, 2007.

MENICUCCI, T. Público e privado na política de assistência à saúde no Brasil: atores, processos e trajetórias. Rio de Janeiro: Fiocruz, 2007.

NUNES, E. A gramática política do Brasil: clientelismo, corporativismo e insulamento burocrático. Rio de Janeiro: Garamond, 2010.

PAIM, R. Reforma sanitária brasileira: contribuição para compreensão e crítica. 2007. Tese (Doutorado em Saúde Coletiva) - Universidade Federal da Bahia, cidade, 2007.

PRATES, A. A. Administração pública e burocracia. In: AVELAR, L.; CINTRA, A. O. (Org.). Sistema político brasileiro: uma introdução. Rio de Janeiro: Konrad Adenauer-Stiftung; São Paulo: Unesp, 2004 .

SILVA, M. K. et al. A dinâmica das relação sociais no Conselho Nacional de Saúde. In: CORTÊS, S. V. (Org.). Participação e saúde no Brasil. Rio de Janeiro: Fiocruz, 2009. p. 73-110.

WEBER, M. Ensaios de sociologia. Rio de Janeiro: Zahar, 1982. 
WEBER, M. Parlamentarismo e governo numa

Alemanha reconstruída. São Paulo: Abril Cultural, 1985 .

WEBER, M. Economia e sociedade: fundamentos da sociologia compreensiva. Brasília, DF: UnB; São Paulo: Imprensa Oficial do Estado de São Paulo, 1999.

WEBER, M. O parlamento como órgão do Estado e o problema da publicidade da administração: a tarefa da seleção dos líderes. In: WEBER, M. Economia e sociedade. Brasília, DF: UnB, 2004. p. 560-568.

Recebido em: 28/04/2012

Reapresentado: 07/06/2013

Aprovado em: 03/07/2013 